\title{
The pharmacokinetics, safety and efficacy of tenofovir and emtricitabine in HIV-1-infected pregnant women
}

\author{
Angela P.H. Colbers ${ }^{a}$, David A. Hawkins ${ }^{b}$, Andrea Gingelmaierc, \\ Kabamba Kabeya ${ }^{d}$, Jürgen K. Rockstroh ${ }^{\mathrm{e}}$, Christopher Wyen ${ }^{\mathrm{f}}$, \\ Katharina Weizsäckerg ${ }^{g}$ S. Tariq Sadiq ${ }^{\text {h }}$, Jelena Ivanovic ${ }^{i}$, \\ Carlo Giaquintoj, Graham P. Taylork, José Moltó', \\ David M. Burger ${ }^{\mathrm{a}}$, on behalf of the PANNA network
}

\begin{abstract}
Objective: To describe the pharmacokinetics of tenofovir and emtricitabine in the third trimester of pregnant HIV-infected women and at postpartum.

Design: A nonrandomized, open-label, multicentre phase IV study in HIV-infected pregnant women recruited from HIV treatment centres in Europe.

Methods: HIV-infected pregnant women treated with the nucleotide/nucleoside analogue reverse transcriptase inhibitors (NRTIs) tenofovir disoproxil fumarate (TDF $300 \mathrm{mg}$; equivalent to $245 \mathrm{mg}$ tenofovir disoproxil) and/or emtricitabine (FTC $200 \mathrm{mg}$ ) were included in the study. Twenty-four-hour pharmacokinetic curves were recorded in the third trimester (preferably week 33) and postpartum (preferably week 4-6). Collection of a cord blood sample and maternal sample at delivery was optional. Pharmacokinetic parameters were calculated using WinNonlin software version 5.3. Statistical analysis was conducted using SPSS version 16.0.

Results: Thirty-four women were included in the analysis. Geometric mean ratios of third trimester vs. postpartum [90\% confidence interval (CI)] were $0.77(0.71-0.83)$ for TDF area under the curve $\left(\mathrm{AUC}_{0-24 \mathrm{~h}}\right) ; 0.81(0.68-0.96)$ for TDF $C_{\max }$ and $0.79(0.70-$ $0.90)$ for TDF $C_{24} \mathrm{~h}$ and $0.75(0.68-0.82)$ for FTC AUC $C_{0-24} \mathrm{~h}$; and $0.87(0.77-0.99)$ for FTC $C_{\max }$ and $0.77(0.52-1.12)$ for FTC $C_{24} \mathrm{~h}$. The viral load close to delivery was less than 200 copies $/ \mathrm{ml}$ in all but one patient, the average gestational age at delivery was 38 weeks. All children were tested HIV-negative and no congenital abnormalities were reported.
\end{abstract}

Conclusion: Although pharmacokinetic exposure of the NRTIS TDF and FTC during pregnancy is approximately $25 \%$ lower, this was not associated with virological failure in this study and did not result in mother-to-child transmission.

(c) 2013 Wolters Kluwer Health | Lippincott Williams \& Wilkins

AIDS 2013, 27:739-748

Keywords: combination antiretroviral therapy, emtricitabine, HIV, mother-tochild transmission, pharmacokinetics, pregnancy, tenofovir

\footnotetext{
${ }^{a}$ Radboud University Nijmegen Medical Centre, Nijmegen, The Netherlands, ${ }^{b}$ Chelsea \& Westminster Hospital, London, UK, ${ }^{\mathrm{c}}$ Klinikum der Universität München, Frauenklinik Innenstadt, Munich, Germany, ${ }^{\mathrm{d}}$ Saint-Pierre University Hospital, Brussels, Belgium, 'enniversity of Bonn, Bonn, ' University of Cologne, Cologne, ${ }^{\mathrm{g}}$ Klinik für Geburtsmedizin, Charité Universitätsmedizin, Berlin, Germany, 'St. George's, University of London, London, UK, 'National Institute for Infectious Diseases 'L. Spallanzani', Rome, 'University of Padua, Padova, Italy, ' Imperial College Healthcare NHS Trust, London, UK, and 'Hospital Universitari Germans Trias I Pujol, Badalona, Spain.
}

Correspondence to Angela Colbers, MSc, Department of Pharmacy, Radboud University Nijmegen Medical Centre, Geert Grooteplein Zuid 10, 6525 GA Nijmegen, The Netherlands.

Tel: +3124 3616405; fax: +31243668755; e-mail: a.colbers@akf.umcn.nl

Received: 18 September 2012; revised: 22 October 2012; accepted: 31 October 2012. 


\section{Introduction}

In 2010, approximately 17.5 million women were infected with HIV, most of who were of child-bearing age [1]. It is estimated that 39\% of the European women infected with HIV have a desire for childbearing in the future, which is comparable to HIV-uninfected women [2]. This has also been reported for women infected with HIV in the USA [3] and South Africa [4].

Combination antiretroviral therapy (cART) has been shown to be a highly effective strategy for preventing mother-to-child transmission (PMTCT) of HIV, reducing the risk from 15-40 to less than 2\% [5]. The US Department of Health and Human Services guidelines recommend the inclusion of one or more nucleoside analogue reverse transcriptase inhibitors (NRTIs) with good transplacental passage in the cART regimen, when feasible [6]. The most commonly used NRTIs are zidovudine (ZDV) and lamivudine (3TC), mainly because of the vastly greater clinical experience with these compounds during pregnancy. However, an overview of antiretroviral drugs prescribed during pregnancy between 1995 and 2009 showed an increase in the use of tenofovir disoproxil (TDF)/emtricitabine (FTC) to approximately $30 \%$, whereas the use of ZDV/3TC decreased from approximately 90 to $70 \%$ [7]. This reflects the recommendations for first-line NRTI backbone (TDF/FTC combination) in nonpregnant adults [8]. All four NRTIs cross the placenta well [9-14]. The current summary of product characteristics of Truvada [15] states that its use may be considered during pregnancy, if necessary. Safety issues on the use of antiretrovirals during pregnancy concern exposure of the mother, influence on pregnancy duration and teratogenicity. cART use (especially protease inhibitor based) during pregnancy has been reported to be associated with an increased rate of preterm delivery $(<37$ weeks gestational age) in European studies [16]. Most North American studies have not shown this association $[17,18]$.

The antiretroviral pregnancy registry interim report (up to 31 January 2012) did not detect a two-fold increase in the risk of overall birth defects: the prevalence of birth defects of both TDF and FTC was 2.3\% [19], compared with $2.1 \%$ prevalence of major birth defects in the European general population [20]. Two individual cases of pyelectasis in children born from mothers receiving TDF-containing therapy during pregnancy have been described [21]. In a macaque model, perinatal exposure to very high doses of TDF resulted in bone toxicity in some offspring [22]. This has not yet been reported in humans $[23,24]$, nor in another macaque model [25]. In studies with FTC during pregnancy, no FTC-related congenital anomalies were reported $[26,27]$ and FTC animal studies do not indicate reproductive toxicity [28].

Human physiology alters during pregnancy, potentially affecting the pharmacokinetics of drugs [29-31], mostly resulting in lower exposure of medication during pregnancy.

Pharmacokinetic parameters of chronic exposure to tenofovir (TFV) during pregnancy have been presented as abstracts at conferences only. It was concluded that exposure during pregnancy is lower, but with area under the curves (AUCs) not below the 10th percentile of nonpregnant patients $(2 \mathrm{mg} \cdot \mathrm{h} / \mathrm{l})$ for most women [10]. In studies of single-dose TDF given for HIV PMTCT at onset of labour, doses of 600 and $900 \mathrm{mg}$ TDF, which are higher than that for chronic administration $(300 \mathrm{mg})$, have been used [14,27]. For the $600 \mathrm{mg}$ dose, plasma concentrations were similar to those observed after chronic administration of $300 \mathrm{mg}$ TDF in nonpregnant adults $[12,14]$ and with an initial dose of $600 \mathrm{mg}$ TDF in nonpregnant adults [11]. A population study of 186 women (of whom 46 were pregnant), with a sparse sampling method, showed 39\% higher apparent clearance of TFV in the pregnant women [32].

Pharmacokinetic parameters of chronic exposure to FTC have been reported as lower during pregnancy, but the magnitude of the decrease appears to be small, 10\% [33] to $18 \%$ [26]. When $400 \mathrm{mg}$ is administered at labour initiation, the plasma concentrations appear higher than after chronic administration of $200 \mathrm{mg}$ FTC in nonpregnant adults [34].

As information on pharmacokinetic changes during pregnancy is limited (especially for chronic use during pregnancy) and the use of TDF and FTC during pregnancy is increasing, we studied the effect of pregnancy on TFV and FTC pharmacokinetics.

\section{Methods}

This was a nonrandomized, open-label, multicentre phase IV study in HIV-infected pregnant women recruited from HIV treatment centres in Europe (PANNA network: www.pannastudy.com). The PANNA network is a European network of hospitals collecting pharmacokinetic curves of several antiretroviral drugs during pregnancy in a prospective study. In total, 17 hospitals are involved in the network, data in this publication were collected from 10 hospitals between November 2008 and January 2012.

The study was conducted in compliance with the principles of the 'Declaration of Helsinki'. Informed consent was obtained from each participant before entering the study. The study was approved by the medical ethical committee from each individual centre involved and by the national authorities if applicable. The study was registered at ClinicalTrials.gov under number NCT00825929. 
Patient eligibility included being HIV infected, pregnant, at least 18 years of age at screening and treated with a cART regimen containing TDF and/or FTC for at least 2 weeks before the day of first pharmacokinetic curve evaluation (in the third trimester of pregnancy). Patients were excluded if they had a past medical history or current condition that might interfere with drug absorption, distribution, metabolism or excretion (such as renal failure or hepatic failure) or presented with grade III/IV anaemia (i.e. haemoglobin $<4.6 \mathrm{mmol} / 1$ or $<7.4 \mathrm{~g} / \mathrm{dl}$ ) at screening.

\section{Safety assessments and viral load}

Inclusion screening consisted of medical history, physical examination, serum biochemistry, haematology and qualitative urinalysis, HIV-1 RNA load and CD4 cell count. Analyses for safety assessments were performed by local laboratories. Blood samples for safety assessments were further taken at the visits for pharmacokinetic blood sampling and at delivery (if they delivered at the hospital). Patients were asked for adverse events at each visit, the DAIDS toxicity table (2004) was used to grade the reported adverse events. The HIV-status of the infants was collected.

\section{Pharmacokinetic blood sampling}

A 24-h pharmacokinetic curve was recorded after at least 2 weeks of TDF and/or FTC treatment during the third trimester (preferably at week 33) and at least 2 weeks postpartum (preferably 4-6 weeks postpartum). At delivery (if possible), a cord blood sample and a blood sample from the mother were taken. Concentrations of TFV and FTC in plasma were analysed by the laboratory of the Pharmacy of the Radboud University Nijmegen Medical Centre.

A standard breakfast $(650 \mathrm{kcal} ; 30 \mathrm{~g}$ fat) was served prior to (observed) dosing on the pharmacokinetic days. Six millilitre of blood was collected just before drug intake (predose) and at $0.5,1,2,3,4,6,8,12$ and $24 \mathrm{~h}$ after medication intake (10 samples) at all pharmacokinetic study days. Plasma was separated and stored at $-18^{\circ} \mathrm{C}$ or lower until shipment on dry ice to the central laboratory for analysis.

\section{Analytical and pharmacokinetic methods}

Concentrations of TFV and FTC in plasma were analysed by use of a validated reversed phase high-pressure liquid chromatography method with fluorescence detection.

Sample preparation for TFV consisted of a liquid-liquid extraction. The solution was injected onto a Symmetry Shield RP 18 column $(3.5 \mu \mathrm{m}, 150 \mathrm{~mm} \times 4.6 \mathrm{~mm})$. The flow rate was set at $1.0 \mathrm{ml} / \mathrm{min}$ and TFV was detected using a fluorescence detector $\left(\lambda_{\text {excitation }}=232 \mathrm{~nm}\right.$, $\lambda_{\text {emission }}=420 \mathrm{~nm}$ ). TFV lower limit of quantification (LOQ) was $0.015 \mathrm{mg} / \mathrm{l}$. The linear calibration ranges in plasma were $0.015-1.5 \mathrm{mg} / \mathrm{l}$.
Sample preparation for FTC consisted of a solid-phase extraction. One hundred and ninety microlitres of the solution was injected onto an Atlantis CP18 column $(5 \mu \mathrm{m}, 150 \mathrm{~mm} \times 4.6 \mathrm{~mm})$. The flow rate was set at $1.0 \mathrm{ml} / \mathrm{min}$. FTC was detected using a fluorescence detector $\left(\lambda_{\text {excitation }}=244 \mathrm{~nm}, \lambda_{\text {emission }}=356 \mathrm{~nm}\right)$. FTC LOQ was $0.030 \mathrm{mg} / \mathrm{l}$. The linear calibration ranges in plasma were $0.03-5.0 \mathrm{mg} / \mathrm{l}$. The assays were externally validated through ACTG [35].

Pharmacokinetic parameters were determined using a noncompartmental model in WinNonlin version 5.3 (Pharsight Corporation, Sunnyvale, California, USA). Area under the curve $\left(\mathrm{AUC}_{0-24 \mathrm{~h}}\right)$ using the trapezoidal rule, the trough concentration $\left(C_{24} \mathrm{~h}\right)$ defined as the sample taken at time point $24 \mathrm{~h}$ (or extrapolated if the sample was missing), maximum concentration $\left(C_{\max }\right)$, elimination half-life ( $\left.T_{\text {half }}\right)$, time of maximum concentration $\left(T_{\max }\right)$ and apparent clearance $(C L / F$, being the dose/AUC ${ }_{0-24 \mathrm{~h}}$ ) were determined per individual curve.

\section{Statistical analysis data handling}

Patients for whom a curve was taken during pregnancy were included in demographic, safety analyses and descriptive statistics of the pharmacokinetic parameters. Geometric mean ratios (GMRs) were calculated for the patients with a curve in the third trimester and a postpartum curve. Pharmacokinetic parameters are reported as geometric means with 95\% CIs. GMRs of $\mathrm{AUC}_{0-24 \mathrm{~h}}, C_{\max }, C_{24 \mathrm{~h}}, C L / F$ and $T_{\text {half }}$ of third trimester vs. postpartum were calculated. To indicate whether the pharmacokinetic parameters during pregnancy differed statistically significantly from the postpartum parameters, a paired $t$-test was performed on the log-transformed parameters. Cord blood : maternal blood concentration ratios were determined and described.

\section{Results}

Thirty-four patients receiving TDF and/or FTC during pregnancy from 10 different sites from the PANNA network were enrolled in the study. The characteristics of the patients and pregnancy outcome are depicted in Table 1. Sixteen patients were white, 17 were black and one was of mixed race. Eleven (32\%) patients were treatment naive at conception and 23 were already on cART before pregnancy. Thirty-one out of 34 patients used Truvada. Other NRTIs used were zidovudine $(n=2)$ and lamivudine $(n=1)$. Twenty-four of the patients were on a boosted protease inhibitor based cART, six were on a nonnucleoside reverse transcriptase inhibitor (NNRTI)based cART, four were on the integrase inhibitor raltegravir, one was on raltegravir + protease inhibitor and one was on maraviroc + protease inhibitor. No other concomitant medication was used which could possibly influence TFV or FTC exposure. 
Table 1. Patient characteristics.

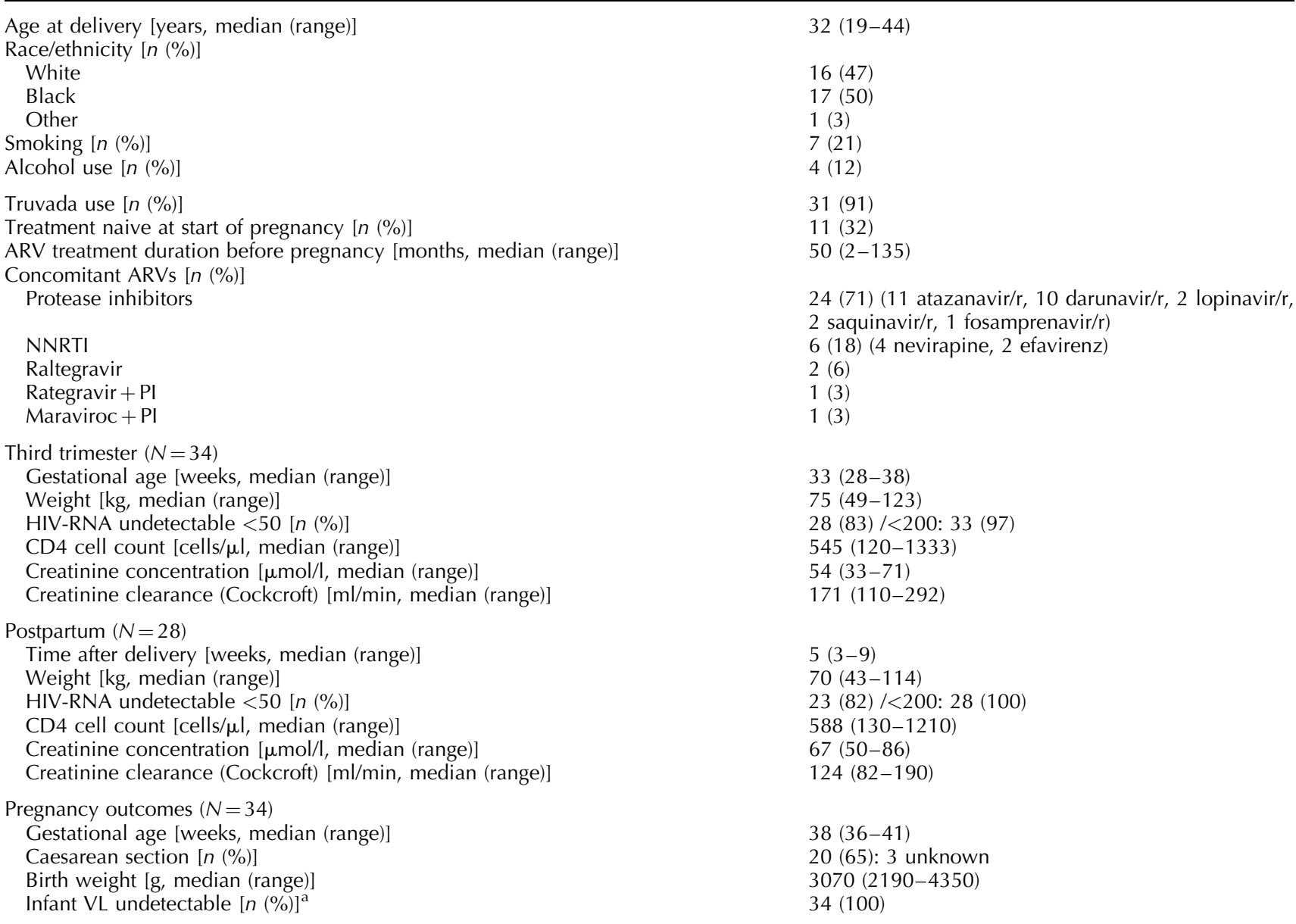

ARV, antiretroviral; NNRTI, nonnucleoside reverse transcriptase inhibitor; PI, protease inhibitor; VL, viral load.

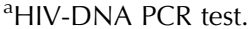

A total of 34 TFV curves were collected in the third trimester (median 3 weeks gestational age) and 27 curves postpartum (median 5 weeks postpartum). For FTC, a total of 27 curves were collected in the third trimester and 24 postpartum. For four patients who had been treated with TDF and FTC, insufficient plasma remained to determine the FTC concentrations. Seven patients did not have a postpartum curve due to several reasons: withdrawn consent $(n=2)$, lost to follow-up $(n=3)$,
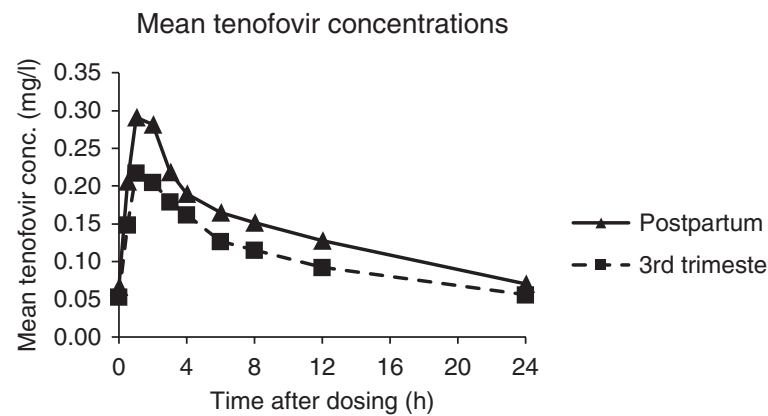

- - 3rd trimester

Fig. 1. Mean concentration-time profiles. changed medication $(n=1)$, and insufficient plasma for analysis $(n=1)$.

\section{Pharmacokinetics}

The mean plasma concentration-time profiles of TFV and FTC in the third trimester and postpartum are presented in Fig. 1; summary statistics of the pharmacokinetic parameters are listed in Table 2. The $\mathrm{AUC}_{0-24 \mathrm{~h}}, C_{\max }, C_{24 \mathrm{~h}}$ of TFV were, respectively, 23,

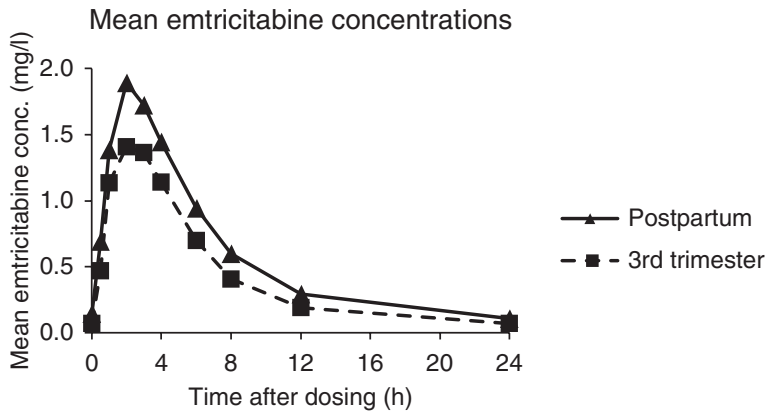


Table 2. Pharmacokinetic parameters.

\begin{tabular}{|c|c|c|c|c|}
\hline & Third trimester $^{\mathrm{a}}$ & Postpartum ${ }^{a}$ & $\begin{array}{l}\text { GM ratio }(90 \% \mathrm{Cl}) \text { of third } \\
\text { trimester : postpartum }\end{array}$ & $P^{\mathrm{b}}$ \\
\hline Tenofovir & $n=34$ & $n=27$ & $n=27$ & \\
\hline $\mathrm{AUC}_{0-24 \mathrm{~h}}(\mathrm{mg} \cdot \mathrm{h} / \mathrm{l})$ & $2.46(2.23-2.66)$ & $3.17(2.86-3.52)$ & $0.77(0.71-0.83)$ & $<0.001$ \\
\hline$C_{\max }(\mathrm{mg} / \mathrm{l})$ & $0.28(0.24-0.31)$ & $0.33(0.29-0.39)$ & $0.81(0.74-0.89)$ & 0.001 \\
\hline$T_{\max }(\mathrm{h})$ & $1.0(0.5-4.0)$ & $1.1(0.5-4.0)$ & & \\
\hline$C_{\text {predose }}(\mathrm{mg} / \mathrm{l})$ & $0.049(0.043-0.056)$ & $0.060(0.050-0.073)$ & $0.81(0.68-0.96)$ & \\
\hline$C_{24 \mathrm{~h}}(\mathrm{mg} / \mathrm{l})$ & $0.052(0.047-0.059)$ & $0.066(0.058-0.076)$ & $0.79(0.70-0.90)$ & 0.003 \\
\hline$T_{\text {half }}(\mathrm{h})$ & $15(14-16)$ & $15(13-17)$ & $1.00(0.87-1.15)$ & 0.987 \\
\hline$C L s s / F(\mathrm{I} / \mathrm{h})$ & $55(51-61)$ & $43(39-48)$ & $1.30(1.20-1.40)$ & $<0.001$ \\
\hline Emtricitabine & $n=27$ & $n=24$ & $n=24$ & \\
\hline $\mathrm{AUC}_{0-24 \mathrm{~h}}(\mathrm{mg} \cdot \mathrm{h} / \mathrm{l})$ & $9.56(8.99-10.48)$ & $13.0(11.8-14.3)$ & $0.75(0.68-0.82)$ & $<0.001$ \\
\hline$C_{\max }(\mathrm{mg} / \mathrm{l})$ & $1.79(1.57-1.99)$ & $2.02(1.78-2.30)$ & $0.87(0.77-0.99)$ & 0.048 \\
\hline$T_{\max }(\mathrm{h})$ & $2.0(0.5-4.0)$ & $2.0(1.0-6.0)$ & & \\
\hline$C_{\text {predose }}(\mathrm{mg} / \mathrm{l})$ & $0.057(0.051-0.084)$ & $0.115(0.088-0.150)$ & $0.57(0.44-0.73)$ & \\
\hline$C_{24 \mathrm{~h}}(\mathrm{mg} / \mathrm{l})$ & $0.052(0.043-0.073)$ & $0.073(0.054-0.098)$ & $0.77(0.52-1.12)$ & 0.232 \\
\hline$T_{\text {half }}(\mathrm{h})$ & $6(5-7)$ & $6(5-6)$ & $1.05(0.91-1.21)$ & 0.570 \\
\hline CLss/F (I/h) & $21(19-22)$ & $15(14-17)$ & $1.34(1.22-1.47)$ & $<0.001$ \\
\hline
\end{tabular}

$\mathrm{AUC}$, area under the curve; $\mathrm{Cl}$, confidence interval; $\mathrm{GM}$, geometric mean.

${ }^{a}$ All values are GM $(95 \% \mathrm{Cl})$ except for $T_{\max }$ [median (minimum-maximum)]

${ }^{b}$ Paired $t$-test on log-transformed data.

19 and 21\% lower during pregnancy compared with postpartum (intrasubject comparison). For FTC, the $\mathrm{AUC}_{0-24 \mathrm{~h}}, C_{\max }, C_{24 \mathrm{~h}}$ were 25,13 and $23 \%$ lower, respectively. For both compounds, the CLss/F is increased during pregnancy ( 30 and $34 \%$ increased for TFVand FTC, respectively), whereas the $T_{\text {half }}$ was not affected. The paired samples $t$-test revealed a significant difference for TFV and FTC AUC ${ }_{0-24 \mathrm{~h}}, C_{\max }$ and $C L s s / F$ as well as TFV $C_{24 \mathrm{~h}}$ between the third trimester and postpartum.

In Fig. 2, the individual $\mathrm{AUC}_{0-24 \mathrm{~h}}$ for TFV and FTC during the third trimester and postpartum are depicted; a subdivision was made for the concomitant use of NNRTI, protease inhibitor and/or integrase inhibitor. No difference between the different cART regimens was observed for TFV or FTC exposure.

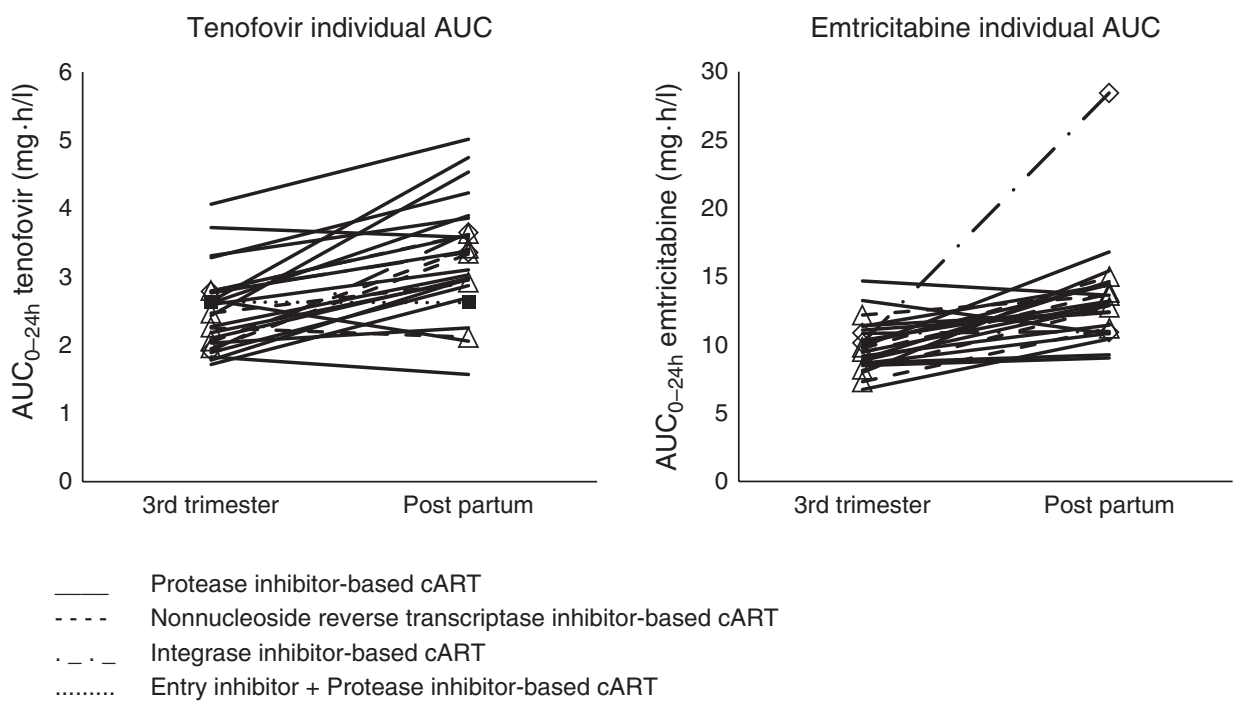

\section{Efficacy and safety}

Sixteen umbilical cord blood samples were collected with matching maternal blood samples. In one cord blood sample (and the matching maternal sample), FTC/TFV concentrations were undetectable. The median time between the reported last dose and delivery was $8.5 \mathrm{~h}$ (range $0-32 \mathrm{~h}$ ) and the median time between cord blood sample and maternal sample was $3 \mathrm{~min}(0-75 \mathrm{~min})$. The median (range) ratio of cord blood: maternal blood was $0.82(0.64-1.10 ; n=14)$ for TFV and $1.63(0.46-1.82$; $n=10)$ for FTC.

HIV viral load close to delivery (median 34 weeks gestational age) was detectable in seven women $(72-272$ copies $/ \mathrm{ml})$. The average gestational age at delivery was 38 (range 36-41) weeks. All children were 
tested HIV-negative and no congenital abnormalities were reported. Four of the infants $(12 \%)$ were born between 36 and 37 weeks gestational age. Three babies had a low birth weight $(<2500 \mathrm{~g})$.

Three patients developed a serious adverse event (SAE). One patient had a hospital admission because she thought the baby was not moving, the baby was born without problems (36.5 weeks gestational age); one patient had a transfusion with packed cells to treat anaemia $24 \mathrm{~h}$ postpartum, anaemia was attributed to blood loss during/ after delivery; and one patient had a postnatal uterus atony, coagulation problems and massive blood loss. All patients recovered. These SAEs were judged by the local investigator not to be related to the cART given. Nine other patients reported adverse events, all were grade 1 or 2 and not or unlikely related to the cART given. These adverse events included back pain, oesophagus pain, inflammation of right eye, urinary tract infection, common cold, gestational diabetes, blood loss during pregnancy, vomiting and nausea; anaemia (2), bronchitis, infection to caesarean section wound, $400 \mathrm{ml}$ blood loss at vaginal delivery and coryza.

Creatinine concentrations and glomerular filtration rate (GFR; using the Cockroft-Gault formula) were determined in the third trimester and postpartum (see Table 1). During pregnancy, creatinine concentrations were lower (median 54 vs. $67 \mu \mathrm{mol} / \mathrm{l}$ ) and estimated GFR higher (171 vs. $124 \mathrm{ml} / \mathrm{min}$ ) compared with postpartum.

\section{Pharmacokinetics-efficacy relationship}

HIV viral loads were detectable $(>50$ copies $/ \mathrm{ml}$ ) for seven patients around delivery. Five out of the seven patients with a detectable viral load were on cART before pregnancy (one on NNRTI-based cART and four on protease inhibitor-based cART) and two started treatment during pregnancy (protease inhibitor-based cART); the treatment duration was 24 and 28 weeks at delivery for these latter two patients. Adherence was checked by asking whether the patients had been taking their medication according to prescription for the last 2 weeks before the measurement. All patients reported to have been adherent to therapy during that period.

Third trimester TFV, geometric means (95\% CI) for AUC $_{0-24 \mathrm{~h}}$ were $2.39(2.17-2.64) \mathrm{mg} \cdot \mathrm{h} / \mathrm{l}$ and 2.72 $(2.03-3.65) \mathrm{mg} \cdot \mathrm{h} / \mathrm{l}$ for patients with undetectable and detectable viral loads around delivery, respectively. For third trimester FTC, geometric means $(95 \% \mathrm{CI})$ for AUC $_{0-24 \mathrm{~h}}$ were $9.41(8.66-10.2) \mathrm{mg} \cdot \mathrm{h} / \mathrm{l}$ (patients with undetectable viral load) and $10.08(7.83-13.0) \mathrm{mg} \cdot \mathrm{h} / \mathrm{l}$ (patients with detectable viral load). In Fig. 3, the individual TFV and FTC $\mathrm{AUC}_{0-24 \mathrm{~h}}, C_{\max }$ and $C_{24 \mathrm{~h}}$ are depicted for patients who had a detectable viral load around delivery compared with the patients who had an undetectable viral load around delivery. For all these parameters, the values are comparable between these two groups.

\section{Discussion}

In this study, we evaluated the pharmacokinetics of TFV and FTC, in the majority of cases combined in Truvada, in 34 pregnant HIV-infected patients, at the third trimester of pregnancy and after delivery. In the third trimester of pregnancy, a decrease in TFV AUC ${ }_{0-24} \mathrm{~h}$, $C_{\max }$ and $C_{24 \mathrm{~h}}(23,19$ and $21 \%$, respectively) was observed as well as a decrease in FTC $\mathrm{AUC}_{0-24 \mathrm{~h}}, C_{\max }$ and $C_{24 \mathrm{~h}}(25,13$ and $23 \%$, respectively). The clearance $(C L s s / F)$ was markedly increased during pregnancy for both compounds (TFV 30\% and FTC 34\%).

TFV and FTC are mainly excreted unchanged in urine, indicating that renal clearance is the major route of elimination. It is known that renal clearance is increased during pregnancy [36], in line with our findings that estimated creatinine clearance increased during pregnancy by around $40 \%$. Although possibly influencing the decreased exposure during pregnancy found in this study, this was not translated into shorter half-life of TFV and FTC. The half-life was determined during a dosing
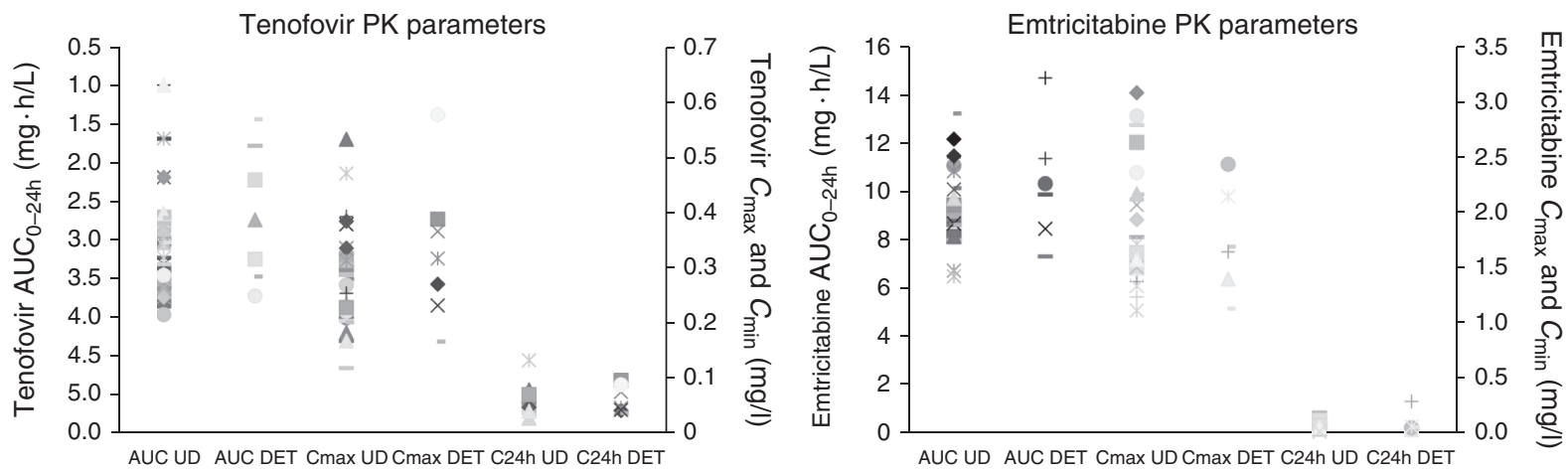

Fig. 3. Comparison of individual pharmacokinetic parameters for patients with and without detectable viral load around delivery. AUC, area under the curve; DET, detectable viral load; UD, undetectable viral load. 
interval, which is possibly not a correct estimate, because the last sample was taken $24 \mathrm{~h}$ after dosing, this means that the entire elimination phase was not covered.

Other physiological changes during pregnancy are reduced intestinal motility, increased gastric $\mathrm{pH}$, a larger plasma volume, increased hepatic blood flow, decreased protein binding and induced hepatic enzymes. The $C_{\max }$ decreased by $19 \%$ for TFV and $13 \%$ for FTC, potentially implying the influence of larger plasma volume and possibly decreased gastrointestinal absorption. However, the absorption was not delayed, as $T_{\max }$ was similar during and after pregnancy for both compounds.

Protease inhibitors are known to increase TFV concentrations [37]. In this study, the TFV $\mathrm{AUC}_{0-24 \mathrm{~h}}$ for patients on an NNRTI regimen are similar to these on a protease inhibitor regimen. Possible explanations for this finding could be a decrease in boosting effect during pregnancy because of the lower exposure to protease inhibitors during pregnancy $[9,38,39]$; furthermore, the number of patients using a nonprotease inhibitor regimen in this study was low (only 18\%), reducing the power to detect a difference.

There is no efficacy threshold level for TFV or FTC. In previous studies with TDF, a threshold of $2 \mathrm{mg} \cdot \mathrm{h} / \mathrm{l}$ for $\mathrm{AUC}_{0-24 \mathrm{~h}}$ [6] (being the 10th percentile of nonpregnant controls) was used and an $\mathrm{AUC}_{0-24 \mathrm{~h}}$ threshold for FTC of at least $7 \mathrm{mg} \cdot \mathrm{h} / 1(\leq 30 \%$ reduction from the normal controls) [26]. Using these thresholds, the study showed that $26 \%$ of the patients receiving TDF did not meet the threshold in the third trimester compared with only $4 \%$ of the patients in the postpartum period. For the patients on FTC, only 4\% did not meet the threshold in the third trimester compared with $0 \%$ postpartum. One of nine of patients with TFV AUC ${ }_{0-24 \mathrm{~h}}$ below the threshold had a detectable viral load around delivery, compared with six of 25 with $\mathrm{AUC}_{0-24 \mathrm{~h}}$ above the threshold. This finding indicates that in this study, TFV $\mathrm{AUC}_{0-24 \mathrm{~h}}$ below the 10th percentile of nonpregnant controls was not associated with virological failure of the mother and did not result in mother-to-child transmission (MTCT).

The reference tenofovir AUC in nonpregnant adults is $3.324 \mathrm{mg} \cdot \mathrm{h} / 1$ with a $C_{\max }$ of $0.326 \mathrm{mg} / 1$, a $C_{\min }$ of

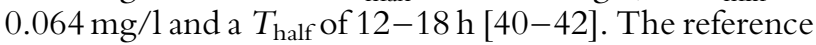
emtricitabine AUC is $10.0 \mathrm{mg} \cdot \mathrm{h} / \mathrm{l}$ with a $C_{\max }$ of

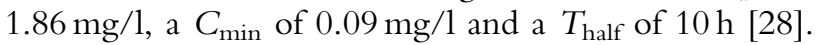
The tenofovir and emtricitabine postpartum pharmacokinetic parameters found in this study are in line with reference values reported in the summary product characteristics. This implies that pharmacokinetic parameters recorded 5 weeks after delivery can be used as reference values for the nonpregnant situation, that is the pregnancy induced physiological changes were not present anymore.
The decreased FTC AUC and $C_{24} \mathrm{~h}$ observed in this study is in line with the decrease reported by Stek et al. [26]. However, we also observed a decrease in FTC $C_{\max }$, which was not observed earlier.

For other NRTIs (zidovudine, lamivudine, didanosine and abacavir), pharmacokinetic studies during pregnancy also reported decreased exposure, without a need for dose alteration [43-46].

For both compounds, placenta passage is good, concentrations in the cord blood are somewhat lower for TFV and approximately similar to the concentrations of the mother for FTC. This is in line with the findings of other NRTIs [47]. In this review, cord blood: maternal ratios for both compounds ranged from 0.60 to 1.6 (with an outlier of 6.0 for tenofovir).

HIV viral load was undetectable ( $<50$ copies $/ \mathrm{ml}$ ) for $79 \%$ patients around delivery and less than 200 copies $/ \mathrm{ml}$ for $97 \%$ of the patients. A possible explanation for the detectable viral load could be shorter treatment duration in these patients. The shortest treatment duration in these patients was 24 weeks, which should be sufficient to suppress the viral load, although both patients were on a protease inhibitor based cART $[48,49]$. The third trimester exposure to TFV and FTC was not lower in patients with a detectable viral load $(n=7)$ compared with the patients who had an undetectable viral load around delivery.

None of the babies had a detectable HIV viral load and no congenital abnormalities were reported. The adverse events observed in this study were judged not be related to the antiretroviral drugs taken but mainly to pregnancy. Although the number of patients in this study is limited, the safety information collected is extensive (safety laboratory and adverse events were collected at each visit). The safety information from this study suggests that the use of Truvada during pregnancy seems to be safe. This reflects the safety reporting on tenofovir use during pregnancy $[23,24,50]$.

None of the available formula for GFR is accurate during pregnancy: the Cockroft-Gault (we used) overestimates the GFR during pregnancy, because the increase in weight is an increase in body water and fat but not in body muscle mass [36]. The only reliable measure for GFR is creatinine clearance by $24 \mathrm{~h}$ urine collection, but this information was not collected in this study.

One of the strengths of this study is that it includes several antiretroviral drugs in one study protocol. Patients using these drugs as part of their cART can be included and their treatment is not adapted for the study. Many patients use more than one antiretroviral drug from the list of medication to be investigated. Another advantage of the study draws from the PANNA network itself and is the 
variation in European and non-European ethnicities available for investigation: approximately $50 \%$ white European and $50 \%$ black patients were included.

A limitation of the study is that no pharmacokinetic curve was collected in the second trimester. We focused on the third trimester as drug disposition of antiretrovirals is thought to be most affected during this period, because of the prominent physiological changes present. Furthermore, in the phase close to delivery, maximum viral suppression and antiretroviral effectiveness is considered important in order to minimize MTCT. Subtherapeutic concentrations in late pregnancy may have a negative effect on antiviral efficacy. This is also a reason for assessing drug exposure during the third trimester of pregnancy.

In conclusion, although pharmacokinetic exposure of the NRTIs TDF and FTC during pregnancy is approximately $25 \%$ lower, this was not associated with virological failure in this study and did not result in MTCT.

\section{Acknowledgements}

A.C., C.G. and D.B. are the primary authors who conceived and designed the study. D.H., A.G., K.K., J.R., C.W., K.W., S.T.S,. J.I., G.T. and J.M. were directly involved in the design and conduct of the PANNA study and included patients on TDF and/or FTC. A.C. was primarily responsible for conducting analyses of the data and the writing of the manuscript. All authors collectively contributed to interpreting results and drafting and editing of the paper.

We thank the patients for participating in this study and the laboratory personnel at the Laboratory of the Department of Pharmacy of the Radboud University Nijmegen Medical Centre for analysing the samples. We thank the staff from the centres participating in the PANNA network (not mentioned in the author's list):

Erasmus MC Rotterdam, The Netherlands: Dr M.E. van der Ende.

Hospital Virgen de las Nieves, Granada, Spain: C. Hidalgo.

Mater Misericordiae University Hospital Dublin, Ireland: Dr J. Lambert.

Radboud University Nijmegen Medical Centre, Nijmegen, The Netherlands: Dr A.J.A.M. van der Ven and Dr A. Warris.

Academisch Medisch Centrum, Amsterdam, The Netherlands: Dr J. Nellen.
St James's Hospital Dublin, Ireland: Dr F. Lyons.

Johann Wolfgang Goethe-Universität, Frankfurt am Main, Germany: A. Haberl.

\section{Conflicts of interest}

Source of support that requires acknowledgement: The PANNA network is financially supported by the 'European AIDS Treatment Network (NEAT)', European Commission, DG Research, 6th Framework program, contract LSHPCT-2006-037570, BMS and MSD.

C.W. has received consulting fees from Boehringer Ingelheim, fees for speaking engagements from BristolMyers Squibb, Gilead Sciences, ViiV Healthcare, MSD, Janssen-Cilag, Essex, Pfizer and Abbott. D.B. has received honoraria and/or study grants from Tibotec, Merck, Abbott, BMS, Roche, Gilead and GSK. J.R. has received honoraria for consulting or speaking fees from Abbott, Boehringer, BMS, Bionor, Gilead, GSK, Janssen, Merck, Pfizer, Tibotec and ViiV.

A.C., D.H., A.G., K.K., K.W., S.T.S., J.I., C.G., G.T. and J.H. have no conflicts of interest to declare.

\section{References}

1. UNAIDS. AIDS epidemic update. http://www.unaids.org/en/ media/unaids/contentassets/documents/unaidspublication/ 2011/JC2216_WorldAIDSday_report_2011_en.pdf. [Accessed 25 July 2012]

2. Fiore S, Heard I, Thorne C, Savasi V, Coll O, Malyuta R, et al. Reproductive experience of HIV-infected women living in Europe. Hum Reprod 2008; 23:2140-2144.

3. Finocchario-Kessler S, Sweat MD, Dariotis JK, Trent ME, Kerrigan DL, Keller JM, et al. Understanding high fertility desires and intentions among a sample of urban women living with HIV in the United States. AIDS Behav 2010; 14:1106-1114.

4. Schwartz SR, Mehta SH, Taha TE, Rees HV, Venter F, Black V. High pregnancy intentions and missed opportunities for patient-provider communication about fertility in a South African cohort of HIV-positive women on antiretroviral therapy. AIDS Behav 2012; 16:69-78.

5. Harris NS, Fowler MG, Sansom SL, Ruffo N, Lampe MA. Use of enhanced perinatal human immunodeficiency virus surveillance methods to assess antiretroviral use and perinatal human immunodeficiency virus transmission in the United States, 1999-2001. Am J Obstet Gynecol 2007; 197:S33-S41.

6. DHHS. Recommendations for Use of Antiretroviral Drugs in Pregnant HIV-1-Infected Women for Maternal Health and Interventions to Reduce Perinatal HIV Transmission in the United States; 14 September 2011; pp 1-207. http:// aidsinfo.nih.gov/contentfiles/PerinatalGL.pdf. [Accessed 1 September 2012]

7. Griner R, Williams PL, Read JS, Seage GR, Crain M, Yogev R, et al. In utero and postnatal exposure to antiretrovirals among HIV-exposed but uninfected children in the United States. AIDS Patient Care STDS 2011; 25:385-394.

8. DHHS. Guidelines for the Use of Antiretroviral Agents in HIV-1Infected Adults and Adolescents, version 27 March 2012. http:// aidsinfo.nih.gov/guidelines/html/1/adult-and-adolescent-treatment-guidelines/0/2012. [Accessed 30 May 2012]

9. Mirochnick M, Capparelli E. Pharmacokinetics of antiretrovirals in pregnant women. Clin Pharmacokinet 2004; 43: 1071-1087. 
10. Burchett S, Best B, Mirochnick M, Hu C, Capparelli E, Fletcher $\mathrm{C}$, et al. Tenofovir pharmacokinetics during pregnancy, at delivery and post partum. In: Proceedings of the 14th Conference on Retroviruses and Opportunistic Infections; 25-28 February 2007; Los Angeles, California; abstract 738b.

11. Mirochnick M, Kafulafula G, Kreitchmann R, Pinto J, Parsons T, Nielsen $\mathrm{K}$, et al. Pharmacokinetics of tenofovir disproxil fumarate after administration to HIV-1-infected pregnant women and their newborns. In: Proceedings of the 16th Conference on Retroviruses and Opportunistic Infections; 8-11 February 2009; Montreal, Canada; abstract 940/T-147.

12. Rodman J, Flynn P, Shapiro D, Bardeguez A, Huang S, Fiscus S, et al. Pharmacokinetics and safety of tenofovir disproxil fumarate in HIV-1-infected pregnant women and their infants. In: Proceedings of the 13th Conference on Retroviruses and Opportunistic Infections; 5-8 February 2006; Denver, Colorado; abstract 121.

13. Flynn P, Mirochnick $M$, Shapiro D, Bardeguez A, Huang S, Fiscus $S$, et al. Single-dose tenofovir disproxil fumarate with and without emtricitabine in HIV-1-infected pregnant women and their infants: pharmacokinetics and safety. In: Proceedings of the 16th Conference on Retroviruses and Opportunistic Infections; 8-11 February 2009; Montreal, Canada; abstract 939.

14. Hirt D, Urien S, Ekouevi DK, Rey E, Arrive E, Blanche S, et al. Population pharmacokinetics of tenofovir in HIV-1-infected pregnant women and their neonates (ANRS 12109). Clin Pharmacol Ther 2009; 85:182-189.

15. EMA. Truvada; Summary of Product Characteristics. http:// www.ema.europa.eu/docs/en_GB/document_library/EPAR _Product_Information/human/000594/WC500043718.pdf 2011. [Accessed September 2012].

16. Martin F, Taylor GP. The safety of highly active antiretroviral therapy for the HIV-positive pregnant mother and her baby: is 'the more the merrier'? J Antimicrob Chemother 2009; 64:895900.

17. Patel K, Shapiro DE, Brogly SB, Livingston EG, Stek AM, Bardeguez $A D$, et al. Prenatal protease inhibitor use and risk of preterm birth among HIV-infected women initiating antiretroviral drugs during pregnancy. I Infect Dis 2010; 201:10351044.

18. Kourtis AP, Schmid CH, Jamieson DJ, Lau J. Use of antiretroviral therapy in pregnant HIV-infected women and the risk of premature delivery: a meta-analysis. AIDS 2007; 21: 607-615.

19. APRegistry. Antiretroviral Pregnancy Registry International Interim Report for 1 January 1989 through 31 January 2012. http:// www.apregistry.com/forms/interim_report.pdf. [Accessed 1 September 2012]

20. EUROCAT. EUROCAT prevalence data tables. http:// www.eurocat-network.eu/accessprevalencedata/prevalencetables. [Accessed 7 September 2012]

21. Sabbatini F, Prati F, Borghi V, Bedini A, Esposito R, Mussini C. Congenital pyelectasis in children born from mothers on tenofovir containing therapy during pregnancy: report of two cases. Infection 2007; 35:474-476.

22. Tarantal AF, Castillo A, Ekert JE, Bischofberger N, Martin RB. Fetal and maternal outcome after administration of tenofovir to gravid rhesus monkeys (Macaca mulatta). I Acquir Immune Defic Syndr 2002; 29:207-220.

23. Nurutdinova D, Onen NF, Hayes E, Mondy K, Overton ET. Adverse effects of tenofovir use in HIV-infected pregnant women and their infants. Ann Pharmacother 2008; 42: 1581-1585.

24. Vigano A, Mora S, Giacomet V, Stucchi S, Manfredini V, Gabiano $C$, et al. In utero exposure to tenofovir disoproxil fumarate does not impair growth and bone health in HIVuninfected children born to HIV-infected mothers. Antivir Ther 2011; 16:1259-1266.

25. Van Rompay KK, Durand-Gasselin L, Brignolo LL, Ray AS, Abel K, Cihlar T, et al. Chronic administration of tenofovir to rhesus macaques from infancy through adulthood and pregnancy: summary of pharmacokinetics and biological and virological effects. Antimicrob Agents Chemother 2008; 52:3144-3160.

26. Stek A, Best B, Luo W, Capparelli E, Burchett S, Hu C, et al. Effect of pregnancy on emtricitabine pharmacokinetics. HIV Med 2012; 13:226-235.
27. Flynn PM, Mirochnick M, Shapiro DE, Bardeguez A, Rodman J, Robbins $B$, et al. Pharmacokinetics and safety of single-dose tenofovir disoproxil fumarate and emtricitabine in HIV-1-infected pregnant women and their infants. Antimicrob Agents Chemother 2011; 55:5914-5922.

28. EMA. Emtriva: Summary of Product Characteristics. http:// www.ema.europa.eu/docs/en_GB/document_library/EPAR__Product_Information/human/000533/WC500055586.pdf. [Accessed 1 December 2011]

29. Anderson GD. Pregnancy-induced changes in pharmacokinetics: a mechanistic-based approach. Clin Pharmacokinet 2005; 44:989-1008.

30. Dawes $M$, Chowienczyk PJ. Drugs in pregnancy. Pharmacokinetics in pregnancy. Best Pract Res Clin Obstet Gynaecol 2001; 15:819-826.

31. Abduljalil K, Furness P, Johnson TN, Rostami-Hodjegan A, Soltani $\mathrm{H}$. Anatomical, physiological and metabolic changes with gestational age during normal pregnancy: a database for parameters required in physiologically based pharmacokinetic modelling. Clin Pharmacokinet 2012; 51:365-396.

32. Benaboud S, Hirt D, Launay O, Pannier E, Firtion G, Rey E, et al. Pregnancy-related effects on tenofovir pharmacokinetics: a population study with 186 women. Antimicrob Agents Chemother 2012; 56:857-862.

33. Best B, Stek A, Hu C, Burchett S, Rossi S, Smith E, et al. Highdose lopinavir and standard-dose emtricitabine pharmacokinetics during pregnancy and postpartum. In: Proceedings of the 15th Conference on Retroviruses and Opportunistic Infections; 3-6 February 2008; Boston, Massachusetts; abstract 629.

34. Hirt D, Urien S, Rey E, Arrive E, Ekouevi DK, Coffie P, et al. Population pharmacokinetics of emtricitabine in human immunodeficiency virus type 1 -infected pregnant women and their neonates. Antimicrob Agents Chemother 2009; 53: 1067-1073.

35. Holland DT, Difrancesco R, Connor JD, Morse GD. Quality assurance program for pharmacokinetic assay of antiretrovirals: ACTG proficiency testing for pediatric and adult pharmacology support laboratories, 2003 to 2004 - a requirement for therapeutic drug monitoring. Ther Drug Monit 2006; 28: 367-374.

36. Maynard SE, Thadhani R. Pregnancy and the kidney. I Am SoC Nephrol 2009; 20:14-22.

37. Kiser JJ, Carten ML, Aquilante CL, Anderson PL, Wolfe P, King $\mathrm{TM}$, et al. The effect of lopinavir/ritonavir on the renal clearance of tenofovir in HIV-infected patients. Clin Pharmacol Ther 2008; 83:265-272.

38. Roustit M, Jlaiel M, Leclercq P, Stanke-Labesque F. Pharmacokinetics and therapeutic drug monitoring of antiretrovirals in pregnant women. Br J Clin Pharmacol 2008; 66:179-195.

39. van der Lugt J, Colbers A, Burger D. Clinical pharmacology of HIV protease inhibitors in pregnancy. Curr Opin HIV AIDS 2008; 3:620-626.

40. EMA. Viread: Summary of Product Characteristics. http:// www.ema.europa.eu/docs/en_GB/document_library/EPAR__Product_Information/human/000419/WC500051737.pdf. [Accessed 1 September 2012]

41. Blum MR, Chittick GE, Begley JA, Zong J. Steady-state pharmacokinetics of emtricitabine and tenofovir disoproxil fumarate administered alone and in combination in healthy volunteers. J Clin Pharmacol 2007; 47:751-759.

42. Ramanathan S, Shen G, Cheng A, Kearney BP. Pharmacokinetics of emtricitabine, tenofovir, and GS-9137 following coadministration of emtricitabine/tenofovir disoproxil fumarate and ritonavir-boosted GS-9137. I Acquir Immune Defic Syndr 2007; 45:274-279.

43. Moodley J, Moodley D, Pillay K, Coovadia H, Saba J, van Leeuwen $\mathrm{R}$, et al. Pharmacokinetics and antiretroviral activity of lamivudine alone or when coadministered with zidovudine in human immunodeficiency virus type 1 -infected pregnant women and their offspring. J Infect Dis 1998; 178:1327-1333.

44. Best BM, Mirochnick M, Capparelli EV, Stek A, Burchett SK, Holland DT, et al. Impact of pregnancy on abacavir pharmacokinetics. AIDS 2006; 20:553-560.

45. Wang Y, Livingston E, Patil S, McKinney RE, Bardeguez AD, Gandia J, et al. Pharmacokinetics of didanosine in antepartum and postpartum human immunodeficiency virus-infected pregnant women and their neonates: an AIDS clinical trials group study. I Infect Dis 1999; 180:1536-1541. 
46. O'Sullivan MJ, Boyer PJ, Scott GB, Parks WP, Weller S, Blum MR, et al. The pharmacokinetics and safety of zidovudine in the third trimester of pregnancy for women infected with human immunodeficiency virus and their infants: phase I acquired immunodeficiency syndrome clinical trials group study (protocol 082). Zidovudine Collaborative Working Group. Am J Obstet Gynecol 1993; 168:1510-1516.

47. Else LJ, Taylor S, Back DJ, Khoo SH. Pharmacokinetics of antiretroviral drugs in anatomical sanctuary sites: the male and female genital tract. Antivir Ther 2011; 16: 1149-1167.
48. Read PJ, Mandalia S, Khan P, Harrisson $U$, Naftalin C, Gilleece $\mathrm{Y}$, et al. When should HAART be initiated in pregnancy to achieve an undetectable HIV viral load by delivery? AIDS 2012; 26:1095-1103.

49. Patel D, Cortina-Borja M, Thorne C, Newell ML. Time to undetectable viral load after highly active antiretroviral therapy initiation among HIV-infected pregnant women. Clin Infect Dis 2007; 44:1647-1656.

50. Gibb DM, Kizito H, Russell EC, Chidziva E, Zalwango E, Nalumenya $R$, et al. Pregnancy and infant outcomes among HIV-infected women taking long-term ART with and without tenofovir in the DART trial. PLOS Med 2012; 9:e1001217. 